\title{
DIVERSIDADE LINGUÍSTICA E A VIOLÊNCIA SIMBÓLICA NAS REGIÕES DE FRONTEIRA BRASILEIRA
}

\author{
DIVERSIDAD LINGUÍSTICA Y LA VIOLENCIA SIMBÓLICA EM LAS REGIONES DE \\ FRONTERA BRASILEÑA
}

\author{
LINGUISTIC DIVERSITY AND SYMBOLIC VIOLENCE IN THE BRAZILIAN \\ BORDER REGIONS
}

\author{
Janaína Moreira Pacheco de SOUZA ${ }^{1}$ \\ João dos Santos BARROS ${ }^{2}$
}

RESUMO: O presente artigo tem como finalidade apresentar um breve panorama do cenário acerca da educação linguística que vem sendo oferecida nas escolas de fronteira brasileira, especificamente na região Norte. Os aportes teóricos que norteiam esse estudo foram baseados em pesquisadores da área da linguística aplicada e da sociolinguística e, para discutir o poder simbólico instaurado nas instituições de ensino, utilizou-se Bourdieu (2007) e Foucault $(1999,2001)$. Pretende-se estabelecer uma reflexão crítica sobre a situação em que se encontra os profissionais que atuam em escolas de contextos de minoria, contribuindo assim para um questionamento sobre a necessidade de se estabelecer políticas públicas voltadas a realidade local.

PALAVRAS-CHAVE: Fronteiras brasileiras. Política linguística. Formação de professores. Violência simbólica.

RESUMEN: El propósito de este artículo es presentar un breve panorama del escenario a respecto de la educación linguística que se ha ofrecido en las escuelas de la frontera brasileña, especificamente en la región Norte. Los aportes teóricos que orientan este estudio se basaron en investigadores del campo de la lingüística aplicada y de la sociolingüística y, para discutir el poder simbólico establecido en las instituciones de enseñanza, se utilizaron Bourdieu (2007) y Foucault (1999,2001). Se pretende establecer una reflexión crítica de la situación actual de los profesionales que trabajan en las escuelas en contextos en que hay minorías, contribuyendo asi a cuestionar la necesidad de establecer políticas públicas centrado en la realidad local.

PALABRAS CLAVE: Fronteras brasileñas. Política lingüistica. Formación de profesores. Violencia simbólica.

1 Universidade do Estado do Rio de Janeiro (UERJ), Maracanã - RJ - Brasil. Professora Adjunta do Departamento de Estudos Aplicados ao Ensino na Faculdade de Educação da UERJ. Doutora em Educação. ORCID: https://orcid.org/0000-0002-3826-7144. E-mail: janamoreira91@gmail.com

${ }^{2}$ Universidade do Estado do Rio de Janeiro (UERJ), Maracanã - RJ - Brasil. Doutorando no Programa de pósgraduação em educação (ProPEd). Professor de Língua Portuguesa e Literatura. ORCID: https://orcid.org/00000002-9592-6468. E-mail: joao-pib@hotmail.com 
ABSTRACT: This article aims to present a brief overview of the scenario about language education that has been offered in Brazilian border schools, specifically in the North region. The theoretical contributions that guide this study were based on researchers in the field of applied linguistics and sociolinguistics and, to discuss the symbolic power established in educational institutions, Bourdieu (2007) and Foucault $(1999,2001)$ were used. It is intended to establish a critical reflection on the situation that finds professionals who work in schools of minority contexts thus contributing to a question about the need to establish public policies focused on the local reality.

KEYWORDS: Brazilian borders. Linguistic policy. Teacher training. Symbolic violence.

\section{Introdução}

Historicamente, a nossa sociedade é marcada pelos esforços de criar uma equivocada imagem da unidade linguística nacional, esquecendo-se de que a história nos revela o entrecruzamento de diversos povos, gerando uma identidade pluriétnica na formação da sociedade brasileira.

Essa visão de brasilidade construída a qual foi entregue a nós, brasileiros e brasileiras, ancora-se em diversas intervenções governamentais e sociais sobre as línguas. Moura (2009) indica que há registros dessa política intervencionista que institui o português como única língua oficial ao mesmo tempo em que se esforçava por apagar as línguas minoritárias. Afirma que, na prática, isso refletiu no uso exclusivo do português como língua de instrução nas escolas públicas em todos os estados do Brasil.

Outro fato importante que deve ser evidenciado sobre a política linguística que há tempos visa manter o status da língua portuguesa, ocorreu no período de 1935 a 1937, pelo Estado Novo. Nesse período as escolas de comunidades formadas por imigrantes, chamadas 'escolas étnicas', foram transformadas em escolas públicas e obrigadas a ter um ensino exclusivo em Língua Portuguesa. Essa proibição ficou conhecida como 'Campanha de Nacionalização' e teve como objetivo desenvolver a identidade nacional de todos os estrangeiros residentes no Brasil (SANTOS, 2012).

É notório que a escolha da língua portuguesa como idioma oficial no Brasil e a proibição de outras línguas serviram a propósitos ideológicos. Essas intervenções geraram uma ilusão de um país unificado, demonstrando que o Brasil é linguisticamente homogêneo e que, devido a isso, possui uma identidade única. Entretanto, apesar do esforço estabelecido de se criar essa crença, os cenários de fronteira surgem para desmitificá-la, trazendo consigo questões inerentes à formação docente e ao currículo, como tópicos fundamentais para se 
debater, com o intuito de estabelecer planejamentos voltados ao processo ensinoaprendizagem nestas regiões.

Para Coracini (2007), a heterogeneidade e a falta de uma política linguística adequada para a realidade fronteiriça dificultam a tarefa do professor em contextos multilíngues. Ressalta, ainda, que o docente precisa estar preparado para lidar com os conflitos em sala de aula e que estes conflitos, juntamente com a falta de formação adequada do professor, acabam gerando estigmas e preconceitos, os quais são vivenciados pelos alunos, interferindo na (re)construção de suas identidades. A autora aponta para a necessidade de currículos específicos que atendam professores de escolas de fronteira, já que essas regiões são reconhecidas como laboratórios linguísticos naturais devido à sua formação étnico-linguística, resultante do fluxo migratório. Cita também a necessidade de se obter um material didático próprio para essas escolas que trate da realidade dessas regiões, com uma abordagem devida acerca da cultura e a história dos países fronteiriços, sem que haja uma visão nacionalista causadora de estigmas, preconceitos e exclusão.

Cavalcanti (1997) e Souza (2019) apontam para a necessidade de inserir estudos sobre educação em contextos de minorias nos cursos de formação de professores. Para as pesquisadoras, falar sobre educação em contextos bilíngues no Brasil é uma necessidade com o qual nos deparamos a cada momento em que professores encontram, cada vez mais, em suas salas de aula, estudantes que não têm o português como primeira língua. Para elas, estudos sobre essa realidade ainda são escassos no Brasil e, por isso, os cursos de formação de professores precisam investir em bases teóricas que contemplem essa temática.

A desigualdade no cenário de educação para minorias fica ainda mais evidente quando se percebe o modo como as escolas lidam com o bilinguismo nas fronteiras. Percebe-se que o ensino da língua na escola é sempre voltado para um falante nativo ideal e para uma comunidade de fala homogênea (SOUZA, 2019).

Esse cenário é visto em várias fronteiras brasileiras, porém o foco de análise desse estudo é uma fronteira situada no norte do Brasil, no estado de Roraima, onde dois países estabelecem uma interrelação fronteiriça, Lethem (República Cooperativa da Guiana) e Santa Elena de Uairén (Venezuela).

Conforme Silva (2017, p. 7), o fluxo migratório dessa região é intenso porque a condição "econômica, social e de segurança faz com que muitos venezuelanos deixem seu país em busca de outras localidades, como o Norte do Brasil, mais precisamente Roraima". Nesse mesmo movimento, estão os guianenses que, nos últimos anos migraram para Roraima, 
com o propósito de conseguir novos empregos e oportunidades, considerando que, na cidade de Lethem, o mercado de trabalho é insuficiente para toda a população.

\section{$O$ contexto educacional das cidades-gêmeas: Bonfim $x$ Lethem e Pacaraima $x$ Santa Elena de Uairén}

O espaço fronteiriço entre o Brasil, Guiana e Venezuela vem sendo modificado em função dos avanços tecnológicos e da comunicação. A imigração para o Brasil, por sua vez, é impulsionada pelas redes de comércio e de serviços que não exigem um alto nível de qualificação profissional, considerando o número crescente de venezuelanos que cruzaram a fronteira em busca de emprego e para fugir da crise humanitária que assola o país de origem. Aqueles que não permanecem em Pacaraima (Brasil), têm Boa Vista, capital de Roraima, como primeira opção. Muitos grupos migram em busca de construir uma vida comum no novo espaço de habitação, criam estratégias de convivência e comunicabilidade, porém não excluem seus costumes, sua língua e práticas sociais. A proximidade entre os dois municípios e a valorização da moeda brasileira fizeram com que houvesse uma migração expressiva de guianenses para o Brasil.

O trânsito fronteiriço também se faz por busca de escolas no Brasil e se deve por diversas razões, dentre as quais é importante destacar: aprender segunda língua, conseguir emprego, ter maior contato com a população e com isso aprender e entender os códigos da cultura urbana brasileira, migração de familiares em busca de melhores condições de vida, casamentos interétnicos, políticas públicas que acabam ajudando os estudantes e os familiares e vislumbre de uma continuidade nos estudos, já que nos países vizinhos este acesso está cada dia mais difícil.

O contato diário entre os professores, alunos brasileiros com guianenses, e, brasileiros com venezuelanos, se dá prioritariamente em língua portuguesa, sendo que, em algumas situações, alguns professores solicitam auxílio de alunos que se comunicam fluentemente nas duas línguas. Outro fator relevante é que muitas vezes os alunos estrangeiros são convidados "a abdicar do inglês" durante o período em que estão na sala de aula, partindo do princípio que, para dominar uma outra língua, ele deve falar e pensar na língua que quer aprender, no caso o português. A mesma realidade é vivenciada por alunos venezuelanos estudantes das escolas públicas de Roraima, seja em Pacaraima ou Boa Vista, de modo que o ensino de língua portuguesa solapa a língua materna dos alunos, obrigando-os a se comunicar, ler e escrever apenas em português. 
Situações como estas nos levam a refletir sobre a formação do professor. Será que ele/ela não está sendo preparado academicamente para enfrentar as questões linguísticas que surgem dentro de sua sala de aula? Será que o currículo que lhe foi oferecido é inadequado ou inconsistente para sua atuação profissional? Como as universidades estão preparando os profissionais da área de Letras para lidar com a diversidade linguística presente nas escolas?

Segundo Santos (2012), o ambiente linguístico da fronteira Brasil-Guiana pode ser considerado atípico do restante do país, já que nesta região há treze línguas diferenciadas, sabendo-se que pelo menos cinco delas se mantém ativas, destacando que, duas são relevantes: o português e o inglês.

Mesmo diante desse fato, alguns currículos escolares são tendenciosos em não reconhecer o plurilinguismo no Brasil, apesar da Constituição de 1988 (BRASIL, 1988) e da LDB (BRASIL, 1996) validarem à diversidade linguística presente no nosso país. Infelizmente, a negação ao diferente e falta de políticas públicas que viabilizem fronteiras como a do Brasil com os países vizinhos fazem com que situações paradoxais sejam apontadas. Para dar legalidade às afirmações, faz-se necessária a observação de Santos (2012, p. 76) ao descrever sobre a diversidade linguística do município de Bonfim - município que faz fronteira com a Guiana:

Na primeira etapa da pesquisa foram consultadas as secretarias de educação, estadual e municipal, com o objetivo de obter as informações iniciais sobre a rede escolar e as devidas autorizações para as visitas às unidades escolares. Nessa etapa, foi notória a negação da diversidade linguística pela Secretaria Estadual de Cultura e Educação, especialmente quanto à possibilidade de existir no espaço escolar alunos que não falam a Língua Portuguesa por serem indígenas, por serem oriundos dos países vizinhos ou por serem surdos. A Secretaria Municipal de Educação de Bonfim reconhece a diversidade linguística existente nas escolas municipais, porém não possui informações estatísticas sobre quais são as línguas faladas nas escolas e nem mesmo sobre quais são as ações desenvolvidas para garantir o ensino proficiente da Língua Portuguesa. A existência da diversidade linguística, negada em alguns níveis de administração escolar, é confirmada pela comunidade em geral e é facilmente percebida durante os primeiros momentos de observação nas escolas do município de Bonfim (SANTOS, 2012, p. 76).

Observa-se através da citação da autora, que nem mesmo os órgãos públicos responsáveis pelo reconhecimento da diversidade em Bonfim o fazem. Contextos diferenciados como esse aqui apontado merecem destaque para que haja um repensar sobre a estrutura educacional que temos e avaliar se elas estão atendendo às necessidades existentes dos estudantes matriculados nessas escolas. 
As fronteiras brasileiras apresentam uma realidade linguística diferenciada de outras regiões do país. O contato entre línguas minoritárias e o português considerado padrão faz com que haja uma relação de "poder" dentro das instituições, eximindo muitas vezes o direito do aluno de aprender adequadamente e de conviver naturalmente com seus pares. Pires-Santos (2004) cita que os alunos provenientes de outros países, além de enfrentarem problemas com a língua portuguesa padrão escrita, enfrentam problemas com o preconceito e acabam sentindo vergonha da própria identidade, criando assim, outra "fronteira" dentro da própria sala de aula. De acordo com Fiorin (2009), "há um silenciamento ainda mais pernicioso, é aquele que reduz seres humanos ao silêncio, por não dominarem certas práticas de linguagem: por exemplo, a escrita, certos discursos, certos modos de dizer" (p. 151).

Bourdieu (2007) explica essa relação de poder existente no sistema educacional. Para ele

[...] o sistema escolar cumpre uma função de legitimação cada vez mais necessária à perpetuação da "ordem social" uma vez que a evolução das relações de força entre as classes tende a excluir de modo mais completo a imposição de uma hierarquia fundada na afirmação bruta e brutal das relações de força (BOURDIEU, 2007, p. 311).

Esse tipo de ação pedagógica é nomeado por Bourdieu como "violência simbólica". Nestas situações, a escola exerce um poder arbitrário, fazendo com que aqueles que já possuem um domínio da língua instituída como oficial sejam sempre beneficiados e que aqueles que estão se inserindo no novo ambiente tenham que aprender novos padrões e modelo de cultura escolar. Nesse contexto, torna-se bem mais fácil para o aluno que domina a língua portuguesa alcançar o sucesso escolar, já que, para ele, não existe a necessidade de aprender uma nova maneira de pensar, de falar, de socializar e de interagir dentro do grupo dominante. Desse modo, a escola consegue reproduzir, através da violência simbólica, as relações de dominação, fazendo com que a necessidade da classe dominante, que neste caso são os falantes nativos da língua portuguesa, seja sempre privilegiada.

Neste sentido, a equidade formal dentro das escolas é estabelecida, pois tende a favorecer sempre os mais favorecidos e desfavorecer os mais desfavorecidos, privilegiando os mais privilegiados e tratando como iguais os que são diferentes. Os alunos que têm como primeira língua o português e que dominam as regras da cultura escolar como uma cultura 'natal' recebem um benefício em relação aos demais que chegam ali legitimados com uma língua e uma 'cultura estrangeira'. A escola cumpre, assim, a função de legitimação das desigualdades sociais. 
Outro importante autor que contribuiu para estudos relacionados às classes desfavorecidas dentro do ambiente escolar foi Michel Foucault. Para ele, “o poder está em toda parte; não porque englobe tudo e sim porque provém de todos os lugares". (FOUCAULT, 2001, p. 89). A escola é apresentada como instituição detentora desse "poder", onde se cumpre um papel uniformizador de condutas, exercendo domínio sobre os corpos.

$\mathrm{Na}$ análise foucaultiana, o poder compreende os processos punitivos desde à Idade Média à Modernidade e suas instituições. Para Foucault (1999), o poder é um exercício, não uma propriedade. Esse exercício se concentra nas relações sociais, imanente dos contextos em que atua, logo, é histórico, espacialmente localizado, em períodos determinados. Por se exercer em ambientes de forças tensionadas, como no caso das línguas em contato, também pode confrontar e negociar. Portanto, as lutas e resistências são premissas do poder que dá nas relações entre os indivíduos e suas diferenças. As instituições reguladoras do corpo social, são, intrinsecamente, um poder disciplinar invisível, ofensivo e segregador.

Foucault (1999) reforça que o exercício do poder ocorre em decorrência de mecanismos, sendo o dispositivo, o principal deles. O dispositivo, por sua vez, é qualquer coisa imaginável em sua funcionalidade. No caso da língua como dispositivo de poder, a estratégia funcional é 'eliminar as diferenças', a partir da demanda crescente de alunos provenientes de culturas linguísticas distintas, heterogêneas. Aliás, na concepção do autor, os dispositivos são conjuntos representados tanto pelo dito quanto pelo não dito, assim, as representações da língua, no contato geral da linguagem, também estão inseridas no exercício de poder.

O fato é que as relações são determinantes para a ação de poder e, nessa discussão, Foucault (1999) constata que cada sociedade tem sua 'política geral de verdade', ou seja, cada sociedade decide, por meio de dispositivos, aparatos e procedimentos, quais discursos, identidades ou sistemas serão aceitos como verdadeiros. A língua do colonizador, inexoravelmente, exercerá poder sobre as demais línguas existentes em um país ou as que provém de outras nacionalidades.

O reconhecimento da diversidade cultural e linguística das regiões de fronteira é uma causa plausível a ser discutida no âmbito da educação contemporânea. As diferentes necessidades de aprendizagem que distintos grupos expressam no interior da nossa sociedade fazem com que educadores necessitem compreender os problemas que estão ao seu redor e, para que isso ocorra, necessitamos de formação especializada em contextos de minoria, escolas preparadas para receber a diversidade e políticas públicas que viabilizem o processo de legitimação dessas situações. 


\section{A violência simbólica da norma linguística do português e sua representação gramatical}

Uma forma sutil de violência simbólica é aquela emprega na escola como imposição da língua sobre os alunos oriundos da imigração, tornando o ensino da norma-padrão como um modelo de repressão, ultrapassado e firmado numa estrutura inflexível da língua. A diversidade e a subjetividade dos sujeitos não permitem que eles sejam postos em grupos homogêneos, com base apenas no discurso da igualdade, sem considerar os contextos sóciohistórico-linguístico e cultural.

Rancière (2005, p. 11), alerta sobre a reprodução sistemática da escola e da sociedade quanto à busca pela igualdade. "Quem estabelece a igualdade como objetivo a ser atingido, a partir da situação de desigualdade, de fato a posterga até o infinito. A igualdade jamais vem após, como resultado a ser atingido. Ela deve ser sempre colocada antes". E completa que "É uma questão política saber se o sistema de ensino tem por pressuposto uma desigualdade a ser 'reduzida', ou uma igualdade a ser verificada" (p. 12).

O autor faz, também, uma observação sobre o ato de instruir e seu significado, inclusive, que pode ser interpretado de formas distintas, na medida em que pode "confirmar uma incapacidade pelo próprio ato que pretende reduzi-la ou, inversamente, forçar uma capacidade que se ignora ou se denega a se reconhecer e a desenvolver todas as consequências desse reconhecimento". A esses dois atos, ele denomina como "embrutecimento" e "emancipação", de modo que, “[...] Os amigos da igualdade não têm que instruir o povo, para aproximá-lo da igualdade, eles têm que emancipar as inteligências, têm que obrigar a quem quer que seja a verificar a igualdade de inteligências" (p. 12).

Um outro aspecto a ser discutido quando falamos de estudantes que advêm do processo de imigração é o fato de eles terem sido alfabetizados na sua língua materna e se deparam com a diferença das línguas quando chega ao Brasil, precisando se adequar às aulas de gramática do português e ao idioma do país em que estão vivendo. A experiência do professor revela a necessidade de, em certas ocasiões, executar um plano de letramento, na intenção de minimizar o drama do aluno se integrar.

Para Costa (2004), o indivíduo seria visto como alfabetizado/letrado quando domina, codifica ou decodifica os sinais gráficos de uma determinada língua, sendo capaz de ler e escrever. Por outro lado, Senna (2001 p. 36, tradução nossa), explica que

[...] o ponto de partida para desenvolvimento do letramento, consiste na tomada de consciência sobre a natureza social do sujeito e, a partir dela, construir uma identidade que mescle - sem perdas - duas perspectivas de 
operar o pensamento: a sua própria, oral e legitimamente reconhecida como capaz de produzir conhecimentos, e a do outro, científica, capaz de the permitir compreender o mundo de forma mais organizada e atuar de forma mais planejada.

Nessa mesma direção, Leal (2004, p. 53) constata:

Se letrar, do ponto de vista social, é perceber o que acontece na sociedade quando esta se apropria das práticas de escrita, sabemos que a análise desse letramento em determinados espaços nos revelará resultados diferentes, porque, para além do que se aprende individualmente, os recursos ao letramento são profunda e marcadamente desiguais. O letramento não é uma abstração. Ao contrário, é uma prática que se manifesta nas mais diferentes situações, nos diversos espaços e nas diferentes atividades de vida das pessoas, permeado por condições reais.

O autor acrescenta que num mundo em que os direitos são negligenciados e negados, os sujeitos não poderão fazer a leitura da palavra, especialmente quando excluídas socialmente, considerando que o letramento social se dá na possibilidade de o estudante fazer a leitura de mundo, sentindo-se valorizado como humano. "Assim, a palavra seria o instrumento que ganha valor, positividade. Por isso se rejeita uma entrada no mundo da escrita que ganhe o estatuto do meramente funcional. É preciso aprender o código, mas também aprender a validar esse código no âmbito da existência real (LEAL, 2004, p. 54).

Segundo Senna (2007b), o conceito de letramento, por ter seu objeto comprometido, em certo grau, com a estrutura da língua à qual buscamos representação na escrita, não mantém as práticas desenvolvidas na escola e, mesmo que este conceito seja tratado isoladamente no contexto da educação, não se baseia na teoria gramatical, uma vez que desta se espera ao menos que os fenômenos linguísticos evidenciados diariamente pelo professor sejam explicados. Mesmo assim, ainda é preciso pensar que a sociedade brasileira se tornou leitora da escrita, mas suas práticas sociais não estão associadas ao domínio da leitura do código, pelo contrário, a forma oral ganha prestígio e resistência, interferindo na cultura brasileira, sobreposta como marca da cultura europeia, em total entranhamento.

A representação gramatical é resultado desse mergulho na língua cristalizada, da obrigatoriedade da norma como ferramenta enganosa de inclusão. Para Mendonça (2007, p. 33) "posturas que reprimam a escrita do aluno, caracterizando-a como incorreta, feia, cheia de erros, devem estar fora da escola. O erro tem que ser corrigido e a ortografia respeitada, porém o problema está na maneira como isso é feito".

Oliveira (1992), constata, a partir de Vygotsky, a rejeição ao que é fixo e imutável, caso contrário, o psicólogo russo não descreveria o cérebro como um sistema aberto, plástico, 
capaz de se moldar com as experiências históricas de cada indivíduo e seu desenvolvimento individualizado. "Dadas as imensas possibilidades de realização humana, essa plasticidade é essencial: o cérebro pode servir a novas funções, criadas na história do homem, sem que sejam necessárias transformações morfológicas no órgão físico” (p. 24).

Na concepção de Ferreiro e Teberosky (1985), o indivíduo letrado é um sujeito que aprende basicamente através de suas próprias ações sobre os objetos do mundo e que constrói suas próprias categorias de pensamento ao mesmo tempo em que organiza seu mundo (p. 26). Todavia, não podemos negar que a norma-padrão ensinada na escola não considera a condição social dos alunos, especialmente dos imigrantes que têm o português como língua estrangeira. Além disso, em muitos aspectos normativos, o ensino de português é semelhante ao de uma língua estrangeira até para os brasileiros, principalmente os que vivem à margem social, distantes dos contextos em que a variedade que insiste em ser reconhecida é a padrão.

Ribeiro (2004), critica o modelo linguístico empregado pela escola a formulação de que a norma do português e sua representação são os únicos caminhos que professores e estudantes devem trilhar para fugir do fracasso escolar.

A "língua" falada em casa e na sua comunidade, em geral, está bastante distante daquela a ser conquistada na escola. Uma língua estranha (estrangeira) não só em sua estrutura, mas no que diz respeito às competências comunicativa e pragmática que seu aluno deve também dominar através da conquista de um mundo que lhe parece, da mesma forma, distante e não apenas novo (RIBEIRO, 2004, p. 65).

Retomando o pensamento de Senna (2007a), a educação, como fenômeno social, introduz, em sua essência, "práticas e valores científicos de mundo", de tal maneira que o reconhecimento de outros modos de pensar distintivamente daqueles que são culturalmente prestigiados é um fazer inclusivo. (p. 222). Quanto às representações, o autor complementa:

A natureza essencial das representações humanas segue uma orientação subjetivante que é propriamente o inverso do movimento epistemológico do sujeito cartesiano, de modo que os conceitos de mundo subjacentes às chamadas categorias essenciais simplesmente não se aplicam às categorias simbólicas com que se sustentam os conceitos nos variados sistemas de valores socialmente motivados. Foi, entretanto, com base nos conceitos de mundo que sustentam as categorias essenciais que as ciências humanas formularam os seus modelos teóricos e suas categorias descritivas, deste modo salientando particularmente o sujeito cartesiano e seu arquétipo, em detrimento dos sujeitos sociais (SENNA, 2006, p. 6-7).

Um estudo realizado por Sturza (2010) sobre o contato entre línguas (Português e Espanhol) na região de fronteira propõe que o plano enunciativo transforma as línguas num 
sistema mesclado, de forma que uma língua se entrelaça a outra. "Porém, o contato entre gramáticas das línguas não é suficiente para dar conta de uma abordagem que busca, sobretudo, compreender o funcionamento e os efeitos de sentido que mesmo mudanças nas formas linguísticas produzem na relação dos sujeitos com as línguas que às quais está exposto, como no caso da fronteira". Nesse aspecto, a pesquisadora fez a seguinte constatação:

Ao serem tomadas de empréstimo e, até mesmo, sendo incorporadas à língua da fronteira, tais formas linguísticas deslocam seu funcionamento e seu significado da língua fonte, passando o falante a atribuir novos sentidos a essas palavras que agarram para si, tornando-as, assim, constitutivas das práticas linguísticas de que dispõem para comunicar-se (STURZA, 2010, p. 84-85).

Há de ser relatado que os estudantes oriundos de fluxos migratórios, sejam venezuelanos ou guianenses, são identificados politicamente como sujeitos inferiorizados numa hierarquia criada por quem está ao redor desses indivíduos e, em muitos momentos, a língua é utilizada como instrumento de segregação, marcando a separação entre os que compartilham o mesmo espaço escolar. Em 2016, quando do exercício docente, percebemos que alunos, professores e funcionários de uma Instituição de Ensino em Boa Vista/RR, insistiam na prática de desprezar a língua dos imigrantes, sob a justificativa de que não poderiam aceitar que o espanhol interferisse no uso do português, por dificultar a comunicação e impedir que estudantes de outro contexto linguístico aprendessem o idioma "oficial" do Brasil.

As provas aplicadas pelos professores eram rigorosamente corrigidas quando haviam respostas com mesclas do português/espanhol ou português/inglês, motivo pelo qual as questões eram dadas como erradas, mesmo que estivessem corretamente respondidas. Quando as respostas eram totalmente escritas em língua estrangeira, a questão também era desconsiderada, apesar de, naquela ocasião, a resposta estar certa. Nestes casos, falta reflexão e amadurecimento sobre o fato de "ao levar em conta a fronteira social, a questão da identidade dos fronteiriços emerge e explicita-se também na língua, pois, na fronteira, as línguas (e aqui estamos tratando de duas línguas nacionais em contato) são constitutivas das relações dos sujeitos com o seu espaço social" (STURZA, 2010, p. 85). Vale ressaltar que as representações da língua são formas de perpetuar o ideal hegemônico e homogeneizado em detrimento dos sujeitos reais, que estão fora do imaginário eurocêntrico.

Claramente podemos enxergar que as migrações e as relações interpessoais dos sujeitos de fronteira na escola ou fora dela constituem o que Sturza (2010) chama de "espaço 
social periférico" e não apenas um limite de um Estado ou de um país. Por conta da marginalização dessas áreas, a fronteira é tida como "esvaziada de sujeitos históricos, políticos e sociais. Por conseguinte, identificar-se com essa realidade à parte é traduzir-se nela" (STURZA, 2010, p. 89).

Aprofundando essa discussão, García (2010), considera a diferença entre a variedade padrão do espanhol e a língua materna dos alunos argentinos, uma realidade conflitante. Segundo ele, há uma distância entre as duas variedades ao ponto de os estudantes não se reconhecerem como sujeitos representados pela leitura da língua descrita nos livros didáticos. Imaginemos que neste cenário de resistência linguística para os alunos argentinos, colonizados por espanhóis, ainda estão os imigrantes e outros povos que tornam o sistema de ensino do país vizinho parecido com o que vivemos no Brasil, em certo grau de comparação. Sendo assim, a representação gramatical de uma língua é tão cruel para os nativos quanto para os de outras nacionalidades.

Alunos venezuelanos e guianenses não se sentem representados pelo portuguêspadrão. Ao passo que fazem uso da língua standard em seu próprio país, ou seja, nem mesmo o espanhol da Espanha ou o inglês da Inglaterra ou dos Estados Unidos representam a língua que falam e escrevem, respectivamente. Agora, vivem também o dilema de ter que lidar com o português-padrão, diferente daquela língua que aprendem diariamente na rua e nos corredores da escola.

Pensando nisso, Aguirre (2011) afirma que falar na normatização do espanhol como língua suscita certa incomodidade e até mesmo ressentimentos para algumas pessoas, apesar de não ser uma questão nova e que está encrostada há muito tempo nos discursos dos hispanofalantes. No entanto, o conceito da norma linguística, segundo ele, pode ser visto de duas maneiras:

O conceito de norma geralmente inclui duas perspectivas: a norma no sentido prescritivo, ou norma própria, entendida como modelo a seguir, por um lado, e, por outro lado, a norma entendida como realização, como produto linguístico útil para a comunicação em um determinado contexto sociolinguístico, a norma como uso (AGUIRRE, 2011, p. 54, tradução nossa).

Até aqui, os apontamentos que fizemos reforçam aspectos importantes como, por exemplo, a incompatibilidade da norma gramatical e o ensino para alunos imigrantes que, em geral, escrevem e falam com traços de sua identidade linguística; a representação gramatical como figura fantasiosa ante à realidade dos sujeitos da imigração, uma vez que são subjugados pela diferença linguística tanto na escrita quanto na fala; a marginalização que 
empurra os indivíduos das escolas de fronteira para o abismo da inutilidade e do fracasso como estudantes; a desumanização e o desconhecimento das capacidades universais desses estudantes; e, não menos relevante, a violência simbólica que todo esse ambiente produz e reforça as incertezas e inseguranças de quem precisou sair de seu país de origem sem qualquer garantia de que seria acolhido e compreendido em sua subjetividade. Cabe pontuar que o professor tem um papel fundamental nesse contexto de formação dos povos imigrantes na escola brasileira e é sobre isso que discutiremos no próximo tópico.

\section{A formação do professor de línguas como ferramenta de acolhimento}

Trazer a formação do professor como eixo central deste trabalho não tem como pretensão transformá-lo no único agente responsável pelo acolhimento dos imigrantes no âmbito escolar brasileiro, no entanto, também não podemos eximi-lo da incumbência de agir em defesa dos direitos sociais e linguísticos destes alunos. Aliás, um bom professor faz toda a diferença num contexto de sujeitos marginalizados, à medida que o profissional desumanizado fortalece as barreiras existentes entre indivíduos que compartilham espaços em que as línguas estão em contato.

Zambrano (2019, p. 17-18), analisa com precisão a experiências dos imigrantes desde à fronteira até a escola, quando relata que, no caso do povo venezuelano

Ao atravessar a fronteira entre o Brasil e a Venezuela, essas pessoas encontram muitas barreiras, dentre elas, a língua, pois apesar do português e do espanhol serem línguas próximas, ambas românicas, originadas do latim, a língua portuguesa pode ser considerada distante da realidade desses imigrantes. Nesse contexto, surge a necessidade de um ensino de língua portuguesa com um viés social, como uma forma de acolher o imigrante de língua e cultura diferentes. No entanto, poucos professores roraimenses têm formação específica para ensinar português como língua estrangeira, somado ao agravante do contexto de imigração forçada, no qual é necessária uma abordagem diferenciada no ensino de línguas. 
A condição dos sujeitos imigrantes tem de ser vista pelo professor sob a perspectiva do acolhimento linguístico, de modo que seu fazer docente também seja um fazer social, considerando os estudantes como cidadãos sobre os quais incide a ação socioeducativa. De acordo com Costa e Silva (2018, p. 603), a imigração demonstra que "a condição de refúgio está intimamente relacionada à aprendizagem de uma nova língua".

A Língua de Acolhimento (LAc) transcende os conceitos de língua estrangeira (LE) e de Segunda Língua (L2), apesar de ser considerada L2 devido ao fato de os imigrantes estarem em contato constante com a língua do país para onde se moveram. Essa observação ocorre porque a língua de acolhimento tem a característica de promover cidadania, integração, acesso aos direitos individuais e coletivos da sociedade em que os sujeitos estão imersos. Por isso, São Bernardo (2016) afirma que a imigração forçada ou pedido de refúgio torna a situação dos imigrantes diferente daquela que os estudantes de português para estrangeiros vivenciam, sobretudo, porque a aprendizagem de uma segunda língua não carrega consigo a necessidade de sobrevivência.

Cabete (2010, p. 48) complementa que “o desconhecimento da língua poderá representar um obstáculo à comunicação com o Outro, ao conhecimento dos seus direitos e deveres enquanto ator social e criar uma desigualdade onde o imigrante se torna mais vulnerável". Nesse sentido, conforme São Bernardo (2016, p. 65) "para imigrantes e refugiados, a apropriação da língua do país de acolhimento não é meramente um fim, mas um meio de integração".

Nesse processo de ensino-aprendizagem dos imigrantes, é preciso ressaltar as tensões e pressões que os sujeitos envolvidos nesse contexto educacional, especialmente professor e aluno, estão inseridos. Nesse ambiente, o docente não pode esquecer da margem e da periferia sociais que atravessam a vida dos estudantes oriundos da imigração. Amado (2013, p. 3), avalia a importância da LAc para os "que chegam ao Brasil em situação de miséria moral e muitas vezes com pouquíssimos recursos financeiros”. Em Roraima, as iniciativas privada e pública são mais frequentes que as ações de governo.

De qualquer forma, mesmo que houvesse investimento total do Estado, o desafio que o professor enfrenta no cotidiano da escola para ensinar português para os sujeitos da imigração é revestido de um esforço substancial, pois não há uma formação específica para ensino de línguas. Atualmente, a escassez de cursos de Letras que formam profissionais para o ensino de línguas associado ao ensino de português é evidente. Júdice (2016) define como insuficiente o número de cursos específicos para formação de professores que precisam ensinar português como língua não materna. Para Zambrano (2019, p. 20), 
Um dos motivos é que a formação específica em PLE/PLA/PL2 é recente no Brasil. A maioria dos cursos de Letras ainda não tem em seus currículos disciplinas ou conteúdo específico sobre o ensino de português como língua estrangeira, língua adicional, ou ainda, língua de acolhimento. Dessa forma, quando surge a necessidade desse ensino, a tendência é ministrar aula de português como se fosse para falantes nativos, ou seja, como língua materna.

A crítica de Ribeiro (2004) sobre a formação do professor é tão atual que descortina a dicotomia existente entre a teoria aprendida na universidade e a prática docente, com o agravante de que os cursos de graduação não operam a reflexão tão necessária em tempos de crises e conflitos educacionais.

Vê-se, na atualidade, uma tendência a discutir o social (exaustiva e isoladamente) sem inserir à discussão características cognitivas e biofisiológicas dos aprendentes. Isto tem acontecido, principalmente, nos meios acadêmicos da área da Educação em que se encontram realidades desafiantes como a de um aluno formado em Pedagogia discursar com facilidade sobre os problemas sócio-políticos da Educação, mas possuir extrema dificuldade para elaborar e executar um plano de aula de maneira adequada à realidade sociocognitiva de aluno e seus (o do, então, professor) conhecimentos teóricos (RIBEIRO, 2004, p. 73).

Nessa mesma reflexão, o professor deve explorar dinâmicas de ensino fora dos padrões e da fixação empregada pela gramática, por exemplo. Afinal, para que servem os testes prontos se não para dividir os estudantes em grupos de incapazes e capazes? As provas de língua portuguesa, quando aplicadas por um professor movido pela norma-padrão como guia, como única estratégia assumidamente viável, não provam nada em sua totalidade. "A aprendizagem não pode ter sua medição facilmente padronizada. [...] Tenta-se padronizar algo que não é passível de padronização" (RIBEIRO, 2004, p. 90).

É preciso que haja equilíbrio nesse complexo processo educacional no qual o professor está inserido e marcado como responsável pelo aprendizado e formação dos estudantes. Senna (2007a) pontua o fato de as políticas de inclusão social na educação aguardarem respostas que promovam às populações segregadas uma maneira de não "alijá-las da educação formal e, ao mesmo tempo, sem submetê-las a novas práticas de segregação por meio de práticas de aculturação, tendo em vista que estas não mais se sustentam em nenhuma relação dogmática com a cultura científica" (SENNA, 2007a, p. 239).

O autor, ainda, considera dois tipos de educação (formal e acidental), cujos resultados diferem e demonstram como a formação do professor influencia na prática de ensinoaprendizagem. Segundo ele, a educação formal "evoca a figura do profissional, o professor, em sua função consagrada na sociedade moderna", enquanto a educação acidental, evoca "as pessoas, os sujeitos sociais que se colocam frente a frente na sala de aula, não como 
professores e alunos, mas sim, como cidadãos de um mesmo tempo humano" (SENNA, 2007a, p. 48).

No contexto da sala de aula, não cabem o professor e o aluno ideais, pois não há um sujeito incansável com o passar dos dias da rotina escolar, completamente interessado e dedicado, inarrável. Estes são perfis inexistentes de profissional e de estudante. Quando se apresentam desafios de ter, na mesma classe, imigrantes venezuelanos e guianenses, plurais e subjetivamente desenvolvidos, a escolha que resta ao profissional, diante da tensão e da pressão dessa experiência, é refazer e reinventar sua prática.

Por isso, é imprescindível considerar as subjetividades de cada aluno, uma vez que "não se trata de transmitir um conhecimento que o sujeito não teria fora desse ato de transmissão, mas sim de fazer-lhe cobrar a consciência de um conhecimento que o sujeito possui, porém sem ser consciente de possuí-lo" (FERREIRO; TEBEROSKY, 1985, p. 24).

Por outro lado, Ribeiro (2004) alerta sobre os discursos que influenciam a dinâmica das salas de aula de muitas escolas brasileiras e o fazer docente de diversos profissionais da educação.

O discurso de que cada um aprende de uma forma diferente ou diferenciada não pode ser usado como um escudo para o não planejamento das aulas, a não avaliação da aprendizagem de forma cautelosa e o não esforço do aluno (ou mesmo do professor) diante das situações de aprendizagem. Quando isto acontece, torna-se fácil omitir-se diante das responsabilidades de aluno e de professor (RIBEIRO, 2004, p. 90).

Em relação ao apego que o docente tem ao livro didático ou ao programa de ensino de determinada instituição, dificulta o planejamento de aulas que abrangem as carências que precisam ser sanadas durante as aulas. Mendonça (2007, p. 33) afirma que "nenhum material didático é completo, pronto e acabado. Todos são passíveis de serem melhorados e adaptados pelo professor, em função de suas necessidades em sala de aula”. Ensinar, para Senna (2007a, p. 53), é "condição imperativa" que incide na "intenção de integrar-se à sociedade", mas também "levar o outro a viver novos conceitos e a incorporá-los aos anteriores", sob a perspectiva de que o ato de ensinar e aprender são elementos “indissociáveis de um processo de educação para a vida social"'.

Reforçamos, neste aspecto, a constituição dos sujeitos de fronteira, a relação que têm com os demais alunos diante do contato linguístico, dos processos identitários, das formas de aprender e a mobilização que causam ou deveriam causar na educação do país no qual estão vivendo como imigrantes, no "não lugar que o estar na fronteira impõe aos seus habitantes, 
entreverados entre uma língua e outra, revela-se como resultado de um estado de ser”. Mais importante, ainda, é que esse reconhecimento ocorra nos ambientes das instituições escolares, diante do trabalho docente, "quando a língua que o significa como sujeito [...] é estigmatizada, é carregada de preconceitos, de negação da identidade fronteiriça, desse viver entre línguas. $\mathrm{O}$ falante, como tomado por essas línguas, utiliza-as, marcando seu lugar político e identitário" (STURZA, 2010, p. 93).

Além de um modelo teórico-acadêmico, os direitos linguísticos acompanham a movimentação dos povos imigrantes à medida em que avançam para outros países e tornamse, irremediavelmente, um ponto de resistência. "Tais movimentos são, em geral, constituídos por sujeitos que diariamente vivenciam a experiência discriminatória de não serem falantes nativos da língua hegemônica de onde vivem" (SILVA, 2017, p. 665).

Varennes (2015, p. 46, tradução nossa) adverte que,

A utilização da língua das minorias contribui assim para a sua inclusão em todas as facetas da sociedade e promove a coexistência pacífica. Usar somente uma língua oficial pode resultar em sua exclusão desproporcional e potencialmente servir para alienar, criar desvantagem e antagonizar parte da própria população do estado.

"Impuro" e "diabólico" é como Bessa Freire (1983, p. 39) afirma terem sido vistos os falantes de outras línguas, tendo desprezados os fatores históricos e identitários que os cercam na sociedade em que estão inseridos, sem a possibilidade de participação efetiva nos contextos público, tecnológico, científico e político. Assim, as identidades são associadas a um aspecto negativo. Varennes (2015), por sua vez, vê o reconhecimento dos sujeitos como garantia de acesso aos instrumentos de cidadania, tão negados historicamente.

$\mathrm{Na}$ realidade, o professor constata todas as dificuldades, inerentes ao ensino de Língua Portuguesa, apenas quando chega à escola e, somente nela, reformula, refaz e reavalia sua prática, especialmente diante do público que originalmente é oriundo dos países de fronteira, como no caso de Roraima. Nesse propósito, a função do profissional se fundamenta na luta contra a desigualdade de grupos cujo poder político e econômico são determinantes para a exclusão. “[...] são efeitos de uma causa maior, e acontece que os esforços de detê-los são sempre muito difíceis (EDWARDS, 2006, p. 104, tradução nossa).

Por outro lado, Spivak (2014, p. 54) orienta o mediador/professor a não cair na armadilha da mediação na tentativa de representar o aluno e torná-lo um "ser objeto", de tal forma que ao "tentar reinserir o sujeito individual por meio de conceitos totalizadores de 
poder e de desejo", os intelectuais acabam representando a si mesmos" (SPIVAK, 2014, p. $54)$.

Para a sociedade, escola e profissionais das letras ou da educação em geral, o conselho de Piller (2016, p. 5) motiva e traz consigo uma reflexão primorosa, pois, segundo o autor, "se nós não formos capazes de, ao menos, reconhecer as desvantagens e discriminações com base na língua, nós não seremos capazes de trabalhar para uma mudança positiva”.

Apesar de trazer nessa discussão o professor como ponto de referência, não podemos assumir sua prática como moderadora e cumpridora de todas as demandas relacionadas à inclusão de imigrantes das fronteiras de Roraima e do Brasil. Aliás, o foco da discussão é a formação do docente em contraponto à violência simbólica sofrida pelos sujeitos da imigração, todavia, reconhecemos que os profissionais da educação são a ponta de um sistema educacional constituído pelo Estado, seus agentes, políticas públicas e procedimentos que alimentam a escola e o seu fazer diário. Portanto, o professor não deve ser responsabilizado pela ineficácia e deficiência do ensino, mas é responsável por suas próprias reflexões e humanização do trabalho que produz.

\section{Considerações Finais}

Grande parte das situações apresentadas neste breve panorama, devem-se a uma crise de valores na área da educação, que prioriza a "padronização", o "normal", a "massa" e tudo que é "diferente" acaba por se deixar de lado. Diante deste cenário, torna-se relevante suscitar reflexões e tomada de posicionamentos de todos os agentes deste processo. Não cabe aqui expor conclusões ou resultados obtidos, por se tratar ainda de uma pesquisa em construção que visa compreender o "olhar" dos professores que atuam nestes contextos marcados pela hibridização. Acredita-se que, com este estudo, surgirão reflexões e discussões a respeito das dificuldades encontradas pela escola ao se deparar com problemas étnico-linguísticos que geram preconceito e estigmatização.

Ao Brasil e aos estados, especialmente Roraima (cenário desse estudo), propomos reuniões, simpósios, encontros, projetos e cursos de formação de professores para lidar com educação em momentos de crise e/ou conflitos, como no caso do fluxo migratório. Do mesmo modo, devem elaborar legislações específicas para atendimento de alunos imigrantes, uma vez que a demanda crescente deste grupo nas instituições de ensino requer atenção e preparo profissional. 
Quanto às escolas, necessitam reformular os projetos-políticos-pedagógicos, priorizar propostas de inclusão e compreender os imigrantes como parte da instituição, afinal, não estão de passagem e permanecerão por muito tempo, talvez para sempre, como indivíduos da escola brasileira.

Por fim, reforçamos o papel do professor no processo de inclusão e humanização dos sujeitos vulneráveis social, cultural, histórico e linguisticamente. Suas práticas podem direcionar estes alunos aos caminhos da cidadania, do emprego, da universidade e da universalidade. Neste momento em que faltam políticas públicas de acolhimento aos imigrantes, a voz do professor em sala de aula ecoa como diferença, como dissonante.

\section{REFERÊNCIAS}

AGUIRRE, A. F. La norma lingüística del español desde una perspectiva lexicográfica: norma nacional versus norma panhispánica. Normas: Revista de Estudios Lingüísticos Hispánicos, n. 1, 2011. Disponível em: https://ojs.uv.es/index.php/normas/article/view/4647/4506. Acesso: 19 jul. 2021.

AMADO, R. S. O ensino de português como língua de acolhimento para refugiados. In: Revista da SIPLE, Brasília, v. 4, n. 2, out. 2013. Disponível em: http://www.siple.org.br/index.php?option=com_content\&view=article\&id=309:oensino-deportugues-como-lingua-de-acolhimento-para-refugiados\&catid=70:edicao-7\&Itemid=113. Acesso: 19 jul. 2021.

BOURDIEU, P. A economia das trocas simbólicas. São Paulo: Perspectiva, 2007.

BRASIL. Constituição (1988). Constituição da República Federativa do Brasil. Brasília, DF: Senado, 1988.

BRASIL, Lei n. 9.394, de 20 de dezembro de 1996. Lei de Diretrizes e Bases da Educação Nacional. Diário Oficial [da] República Federativa do Brasil, Brasília, DF, v. 143, n. 248, 23 dez. 1996.

CABETE, M.A.C. S. S. O processo de ensino-aprendizagem do português enquanto língua de acolhimento. 2010. Dissertação (Mestrado em Língua e Cultura Portuguesa) Universidade de Lisboa (Ulisboa), Lisboa, 2010.

CAVALCANTI, M. C. Estudos sobre educação bilíngue e escolarização em contextos de minorias linguísticas no Brasil. D.E.L.T.A., São Paulo, v. 15, n. esp., p. 385-417, 1999.

CAVALCANTI, M. C. Formação de professores para contextos bilíngues no Brasil. In: CONFERÊNCIA SOCIEDADE BRASILEIRA PARA O PROGRESSO DA CIÊNCIA SBPC, 49., 1997, Belo Horizonte. Anais [...]. Belo Horizonte, MG, 18 jul. 1997.

CORACINI, M. J. R. F. A Celebração do Outro: arquivo, memória e identidade - línguas (materna e estrangeira), plurilinguismo e tradução. Campinas, SP: Mercado de Letras, 2007. 
COSTA, E. J.; SILVA, F. C. Legislação migratória e português como língua de acolhimento: reflexões sobre políticas linguísticas e lingua(gem). Revista de Divulgação Científica em Língua Portuguesa, Linguística e Literatura, v. 14, n. 23, p. 598-612. 2018.

COSTA, M. V. Mídia, magistério e política cultural. In: COSTA, M. V; VEIGA-NETO, A. (org.). Estudos Culturais em Educação: mídia, arquitetura, brinquedo, biologia, literatura, cinema. 2. ed. Porto Alegre: Editora da UFRGS, 2004, p. 73-92.

EDWARDS, J. Language revitalization and its discontents: an essay and review of Saving Languages: an introduction to language revitalization. In: GRENOBLE, L.; WHALEY, L. (ed.). Saving Languages: an introduction to language revitalization. Cambridge: Cambridge University Press, 2006. p. 101-120.

FERREIRO, E.; TEBEROSK, A. A Psicogênese da Língua Escrita. Porto Alegre: Artes Médicas, 1985.

FILHO, J. C. P. A. Índices nacionais de desenvolvimento do ensino de português língua Estrangeira. In: CUNHA, C. M. J.; FILHO, J. C. P. A. Projetos iniciais em português para falantes de outras línguas. Brasília, DF: EdUnB; Campinas, SP: Pontes Editores, 2007. p. $39-55$.

FIORIN, J. L. Língua, discurso e política. Alea: Estudos Neolatinos, v. 11, n. 1, p.148-165, 2009. DOI: https://doi.org/10.1590/S1517-106X2009000100012

FOUCAULT, M. História e Sexualidade I: a vontade de saber. Rio de Janeiro, Graal, 2001.

FOUCAULT, M. Vigiar e punir: nascimento da prisão. Trad. Raquel Ramalhete. Petrópolis, RJ: Vozes, 1999.

FREIRE, J. R. B. Da "fala boa" ao português na Amazônia brasileira. Revista Ameríndia, n. $8,1983$.

JÚDICE, N. O ensino de Português para Estrangeiros na perspectiva de quem forma professores no Brasil. In: TURAZZA, J. S. et al. (org.) Estudos em português língua estrangeira: homenagem à profa. Dra. Regina Célia Pagliuchi da Silveira. 1. ed. Jundiaí, SP: Paco Editorial, 2016.

LEAL, L. F. V. Sujeito letrado, sujeito total: implicações para e letramento escolar. In: MELLO; M. C. RIBEIRO, A. E. A. (org.) Letramento: significado e tendências. Rio de Janeiro, WAK, 2004.

MENDONÇA, O. S. Percurso histórico dos métodos de alfabetização. Faculdade de Ciências e Tecnologia - Departamento de Educação UNESP. Presidente Prudente: SP, 2007. p. 23-35. Disponível em:

https://acervodigital.unesp.br/bitstream/123456789/40137/1/01d16t02.pdf. Acesso: 07 ago 2021.

MOURA, S. A. Educação Bilíngue no Brasil: Possibilidades e desafios Rumo a uma Sociedade Linguística e Culturalmente Plural. In: SEMANA DA EDUCAÇÃO, 6., 2008, São Paulo. Anais [...]. São Paulo, SP: FEUSP, 2008. 
OLIVEIRA, M. K. Vygotsky e o processo de formação de conceitos. In: PIAGET, V. W. Teorias psicogenéticas em discussão. São Paulo: Summus, 1992.

PILLER, I. Linguistic Diversity and Social Justice: An introduction to Applied Sociolinguistics. New York: Oxford University Press, 2016. DOI: https://doi.org/10.1093/acprof:oso/9780199937240.001.0001

PIRES-SANTOS, M. E. O cenário multilíngüe/multidialetal/multicultural de fronteira e o processo identitário "brasiguaio" na escola e no entorno social. 2004. Tese (Doutorado) Universidade Estadual de Campinas, Campinas, 2004.

RANCIÈRE, J. O mestre ignorante: Cinco lições sobre a emancipação intelectual. 2 ed. Belo Horizonte, MG: Autêntica, 2005.

RIBEIRO, A.E. A. Letramento: significado e tendências. Rio de Janeiro, WAK, 2004.

SANTOS, A. S. Multilinguismo em Bonfim/ RR: O ensino de Língua Portuguesa no contexto da diversidade linguística. 2012. Tese (Doutorado em Linguística) - Universidade de Brasília, Brasília, 2012.

SÃO BERNARDO, M. A. Português como língua de acolhimento: um estudo com imigrantes e pessoas em situação de refúgio no Brasil. 2016. Tese (Doutorado em Linguística) - Universidade Federal de São Carlos, São Carlos, 2016.

SENNA, L. A. G. Categorias e sistemas metafóricos: um estudo sobre a pesquisa etnográfica. Educação em Foco, v. 11-1, p. 169-187, mar./ago. 2006. ISSN 0104- 3293.

SENNA, L. A. G. Letramento e desarrollo humano en contextos interculturales. In: Congresso Internacional Virtual de Psicologia Educativa, 2001, Islas Balleares. Actas [...]. Islas Balleares, Universidad de las Islas Balleares, 2001. Disponível em: https://www.senna.pro.br/biblioteca/cibereduca_new.pdf. Acesso em 10 ago. 2021.

SENNA, L. A. G. Letramento: princípios e processos. Curitiba, PR: Ibpex, 2007a.

SENNA, L. A. G. O conceito de letramento e a teoria da gramática: uma vinculação necessária para o diálogo entre as ciências da linguagem e a educação. Revista Delta, v. 23, n. 1, 2007b. Disponível em: https://www.senna.pro.br/biblioteca/delta_2008.pdf. Acesso em: 20 jul. 2021.

SENNA, L. A. G. Text production, representation of thought and discursive genders in elementary school classes. Social Sciences and Humanities, v. 1, 2019. Disponível em: https://www.sciencedirect.com/science/article/pii/S2590291119300075. Acesso: 28 jul. 2021.

SILVA, J. C. J. Migração forçada de venezuelanos pela fronteira norte do Brasil. In: ENCONTRO ANUAL DA ANPOCS, 41., 2017, Caxambu. Anais [...]. Caxambu, MG, 2017. Disponível em: https://www.anpocs.com/index.php/papers-40-encontro-2/gt-30/gt1626/10744-migracao-forcada-de-venezuelanos-pela-fronteira-norte-do-brasil/file Acesso: 02 ago. 2021. 
SILVA, J. I. O debate sobre direitos linguísticos e o lugar do linguista na luta dos sujeitos falantes de línguas. RBLA, Belo Horizonte, v. 17, n. 4, 2017. p. 663-690. DOI: http://dx.doi.org/10.1590/1984-6398201711347

SOUZA, J. M. P. Ser professora em área de fronteira bilíngue no Brasil: desafios e possibilidades. 2019. Tese (Doutorado em Educação) - Universidade do Estado do Rio de Janeiro (UERJ), Rio de Janeiro, 2019.

SPIVAK, G. C. Pode o subalterno falar? 2. ed. Belo Horizonte, MG: UFMG, 2014.

STURZA, E. R. Espaço de enunciação fronteiriço e processos identitários. Pro-Posições, v. 21 n. 3, 2010, p. 83-96. DOI: https://doi.org/10.1590/S0103-73072010000300006

VARENNES, F. The human rights dimension and challenges of linguistic rights. In: INTERNATIONAL CONFERENCE INTEGRATION AND EXCLUSION: LINGUISTIC RIGHTS OF NATIONAL MINORITIES, 2015, Vilnius. Proceedings [...]. Vilnius, 2015. p. $39-56$.

ZAMBRANO, C. E. G. Português como língua de acolhimento em Roraima: Da falta de formação específica à necessidade social. R E V I S T A X, Curitiba, PR, v. 14, n. 3, 2019. p. $16-32$.

\section{Como referenciar este artigo}

SOUZA, J. M. P.; BARROS, J. S. Diversidade linguística e a violência simbólica nas regiões de fronteira brasileira, Rev. EntreLinguas, Araraquara, v. 7, esp. 6, e021152, dez. 2021. eISSN: 2447-3529. DOI: https://doi.org/10.29051/el.v7iesp.6.15453

Submetido em: $28 / 08 / 2021$

Revisões requeridas em: 12/10/2021

Aprovado em: 25/11/2021

Publicado em: 28/12/2021 